\title{
Percutaneous pedicle screw fixation combined with selective transforaminal endoscopic decompression for the treatment of thoracolumbar burst fracture
}

\author{
Zhangheng Huang ${ }^{1 \dagger}$, Yuexin Tong ${ }^{1 \dagger}$, Zhiyi Fan ${ }^{1}$, Chuan $\mathrm{Hu}^{2}$ and Chengliang Zhao ${ }^{1 *}$ (D)
}

\begin{abstract}
Background: The objective of this study was to evaluate the feasibility, safery, cacy, ard indications of percutaneous pedicle screw fixation (PPSF) combined with selective transio ni, doscopic decompression (TED) in the treatment of thoracolumbar burst fracture (TBLF).

Methods: From August 2015 to October 2018, a total of 41 patients inale-segment TLBF (28 men and 13 women) were enrolled in this study. X-ray and computed tomography ere,obtained before surgery, 1 week after surgery, and 1 year after surgery to evaluate spinal recovery. In addition, we used the visual analog scale (VAS), the Oswestry Disability Index (ODI), the Japanese Orthopedic ASSOC, on score (JOA), and the Frankel classification of neurological deficits to evaluate the effectiveness of the th tmen

Results: The average follow-up time was $22.02 \pm 828$ months the postoperative Cobb angle, vertebral body compression ratio, vertebral wedge angle, mid-sag. I/cana diameter compression ratio, and Frankel grade were significantly improved. There were also signif ant imp vements in the VAS $(7.61 \pm 1.41 \mathrm{vs} .1 .17 \pm 0.80, P<0.001)$, ODI (89.82 \pm 7.44 vs. $15.71 \pm 13.50, P<0.011)$, d JOA $6.90 \pm 2.91$ vs. $24.90 \pm 3.03, P<0.001)$

Conclusions: Our results showed that PPSF comk red with selective TED in the treatment of TLBF had excellent efficacy, high safety, less secondary j jury than other treatments, and a wide range of indications and that it could accurately distinguish patients who a not need spinal canal decompression after posterior fixation. PPSF combined with selective TED is therefore - good cirnce for the treatment of TLBF.
\end{abstract}

Keywords: Percutaneous pedicle syry fixation, Transforaminal endoscopic decompression, Thoracolumbar burst fracture, Three nerve ren ecomisression

2. Theng ruang and Yuexin Tong contributed equally to this work.

'Depa ont of Spine Surgery, Affiliated Hospital of Chengde Medical Univers, y, Chengde 067000, Hebei, China

Full list of author information is available at the end of the article

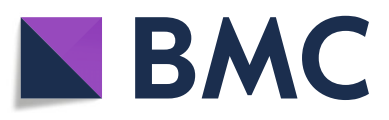

C C The Author(s). 2020 Open Access This article is licensed under a Creative Commons Attribution 4.0 International License, which permits use, sharing, adaptation, distribution and reproduction in any medium or format, as long as you give appropriate credit to the original author(s) and the source, provide a link to the Creative Commons licence, and indicate if changes were made. The images or other third party material in this article are included in the article's Creative Commons licence, unless indicated otherwise in a credit line to the material. If material is not included in the article's Creative Commons licence and your intended use is not permitted by statutory regulation or exceeds the permitted use, you will need to obtain permission directly from the copyright holder. To view a copy of this licence, visit http://creativecommons.org/licenses/by/4.0/ The Creative Commons Public Domain Dedication waiver (http://creativecommons.org/publicdomain/zero/1.0/) applies to the data made available in this article, unless otherwise stated in a credit line to the data. 


\section{Introduction}

Thoracolumbar fractures are the most common spine fractures, with burst fractures accounting for $10-20 \%$ of these fractures [1-3]. Thoracolumbar burst fracture (TLBF) often leads to neurological dysfunction and kyphosis [4]. At present, it is generally believed that surgical treatment is preferred for burst fractures with neurological damage [5]. The main purposes of surgical treatment are to restore vertebral height, lordosis, spinal stability, and decompression of the spinal canal [6]. With the development of percutaneous pedicle screw fixation (PPSF) technology, PPSF has gained increasing recognition for thoracolumbar fractures. Its efficacy is similar to open posterior fixation, but related complications have been significantly reduced $[7,8]$.

PPSF is mainly used for compression fractures and burst fractures without nerve damage or mild nerve damage [9]. There is still some controversy concerning the use of PPSF in the treatment of TLBF with significant neurological impairment. The controversy mainly focuses on whether it is necessary to combine it with spinal canal incision and decompression and how to choose the decompression method. Because PPSF is effective for TLBF treatment in terms of fixation and reduction, it can reset the bone mass protruding into the spinal canal, to a certain extent, and in some cases, sood spinal canal recovery can be achieved without in 1 canal decompression [10]. Therefore, some su geons lieve that TLBF can be treated by posterior $>$ le screl fixation alone without spinal canal incision ana ${ }^{\circ} \mathrm{com}-$ pression [11, 12]. Although the o erall neuro, ogical functions improve significantly afte surgery, there are still many cases where the neurolog fun tion is not recovered or is poorly recovere This is because posterior pedicle screw fixation and redu, $A$ only involve indirect decompression spir al canal, which cannot fully decompress dir $\mathrm{v}$ [ It $t$, nus may delay recovery of the damaged s.mal a and nerve function.

Based on the onsider ${ }^{2}$ ons, the current mainstream view is that TLB must un argo spinal canal decompression at the same time as cure fixation and reduction. The main decor essio mcthods are posterior decompression surrry id anterior decompression surgery [14]. Sufficient SP I cand decompression is conducive to the recovery of $t_{1}$ damaged spinal cord and nerve function [15]. However, at the same time, spinal canal decompression involves great trauma, bleeding, and para-injury, and it may also cause secondary damage to the spinal cord and nerves. Because we cannot accurately distinguish between patients who need direct decompression and those who do not need it, all patients undergo spinal canal decompression. This indicates that this surgical method is not the perfect choice.
To solve the abovementioned complication that accurate decompression cannot be achieved, we propose the concept of PPSF combined with selective transforaminal endoscopic decompression (TED) for the treatment of TLBF. We proposed that PPSF and TED could be performed in different stages. After PPSF is perforr $2 \mathrm{~d}$ at the first stage, the recovery of neurological fun tion and the relief of spinal canal compression shown on stoperative computed tomography (CT) car be evalı a. For patients with satisfactory spinal cara comp ession after indirect spinal canal decompression, no further spinal canal decompression is 1 quired. $T H D$ is conducted at the second stage on'y $\mathrm{w}$ patifnts have indications for further spinal al anpression. This approach can achieve sfective, urate, and minimally invasive spinal canal a ec pression. Here, we systematically reviewed the patient. reated by our method and evaluated its fersibl $y$, safety, and effectiveness to determine the indica he procedure and to formulate standardized treat. nt protocols.

\section{Methods Patients}

Pau ts who met the following inclusion criteria were nclue d in this study: (1) A3 type in the AO classifica- of spinal fracture $[16,17],(2)$ no locked facet joint, (3) a strong will to receive surgical treatment and avoid prolonged bed rest, and (4) had follow-up at $>12$ months. People who met the following criteria were excluded: (1) fractures of $>2$ vertebrae, (2) single-vertebra fracture with a dislocation, and (3) had follow-up at < 12 months.

\section{Surgery procedure}

Forty-one patients underwent PPSF surgery, and fifteen of them underwent further TED surgery after PPSF. The patient was told to lie prone on a radioscopy spinal operating table with their chest, abdomen, and pelvis properly supported by gel pads. Local anesthesia plus intravenous anesthesia were performed (without tracheal intubation; the patient was conscious). After determining the skin entry point using $\mathrm{C}$-arm fluoroscopy, $0.5 \%$ lidocaine was infiltrated and anesthetized to the periosteal surface, layer by layer.

The puncture needle penetrated the vertebral body through the pedicle, the position was confirmed by fluoroscopy, and a guidewire was placed. Several straight hollow pedicle screws of the appropriate size were inserted percutaneously along the guidewire. The injured vertebral body and its proximal vertebral body were implanted obliquely downward with the pedicle screws, and pedicle screws were placed in the distal vertebral bodies in a horizontal or oblique upward direction. The heads of three percutaneous screws on the same side 
were cohesive, and the screw tail that penetrated the injured vertebrae was slightly higher than the height of the two tails of the screws placed on the two sides of the injured vertebrae. A mild lordosis connection rod was used to fix the screws. The tail wire was tightened one by one in order to fix and reduce the injured vertebra. $\mathrm{C}$-arm fluoroscopy was used to determine whether the fracture was reduced and whether the internal fixation was in the right position. The suture incision was then flushed. It was essential to review the X-rays and CT results on the first day after PPSF to evaluate the reduction and recovery of nerve function. If the nerve function was completely recovered, TED surgery was not performed. If there was still significant nerve damage or obvious hip and lower limb nerve stimulation symptoms, the patient was further treated with TED, which was performed within 5 days after the first operation.

The patient lay on the contralateral side. The waist was supported by suitable lumbar padding. The skin entry point was determined by fluoroscopy. The subcutaneous tissue, fascia, and small joint capsule were injected with $0.8 \%$ lidocaine to induce local anesthesia. With the assistance of C-arm fluoroscopy, a puncture needle (size no. 16) was directly percutaneously inserted into the tip of the superior facet. Hollow manual bone drills with diameters of 4,6 , and $8 \mathrm{~mm}$ were used to expand the puncture and perform the foraminoplasty. We inserted a working cannula into the dilated tract through the foramen and extended the distal end of the cannula to the median part of the spinal canal until the tip of the cannula reacb the posterior-superior end of the lower vertebra $(\mathrm{Fi} 1\rangle \mathrm{De}_{-}$ compression was performed to the intervertebral men central canal, and bilateral spinal canals under the 1/6scope. Compressions such as fractures, $1 \mathrm{~h}$ us rin rs, and ligaments in the spinal canal were emove The "three nerve root decompression metho "was usec to ensure sufficient decompression on the cal sac which meant that the entrance exiting ner oo traversing nerve root to the inner ventral of the $\mathrm{a}$ l sac and contralateral traversing nerve roo fully decompressed. Endoscopic examinations ensur no compression remained, such as fracturer. O drainage tube was left in place, and the surgery was

The type of case shown in Fig. 2.

\section{Assessmen of $\mathrm{Cl}_{1}$,ical outcomes}

We collected the data of disease histories and physical exa nations of patients included in our study. A visual

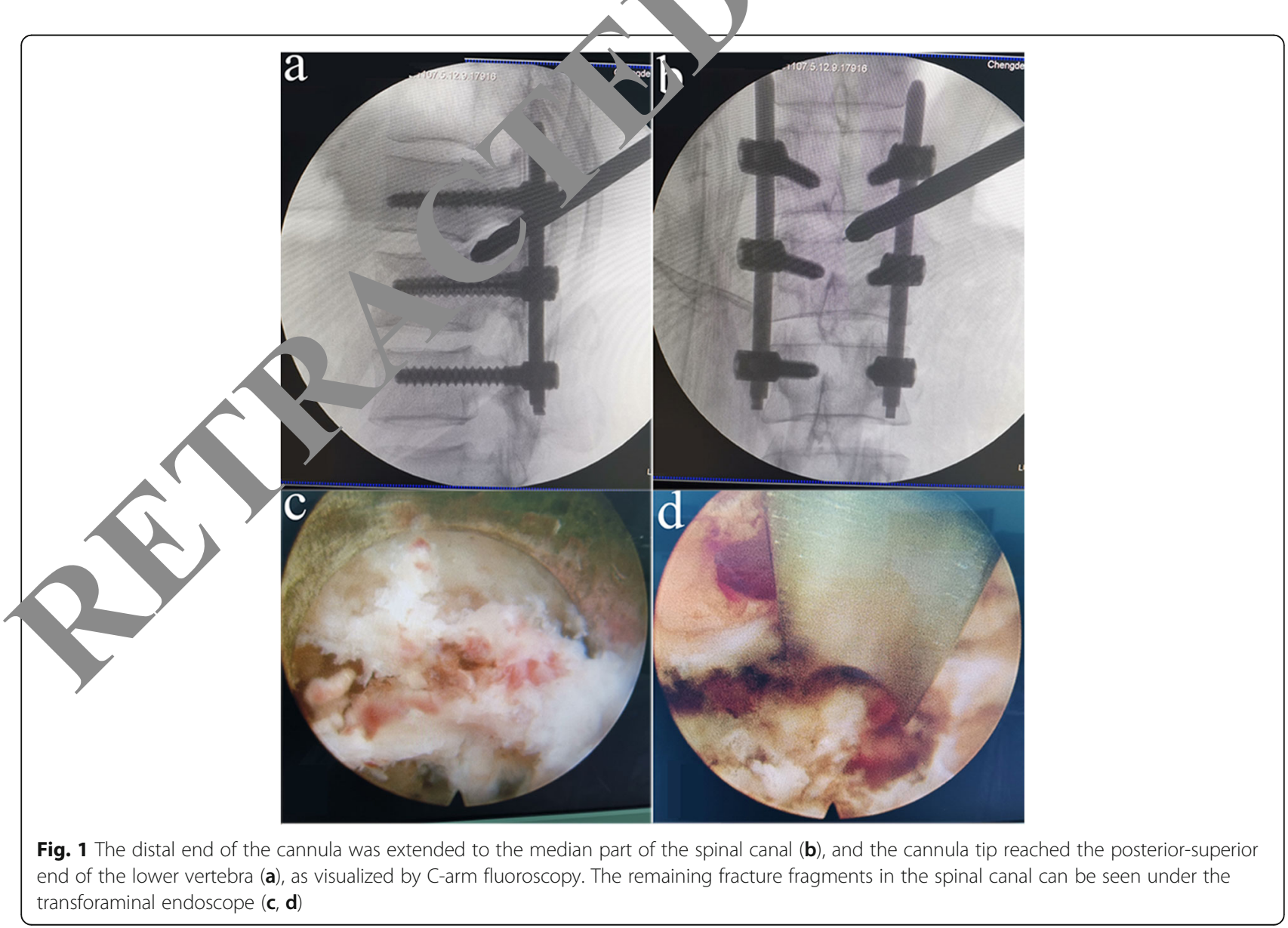




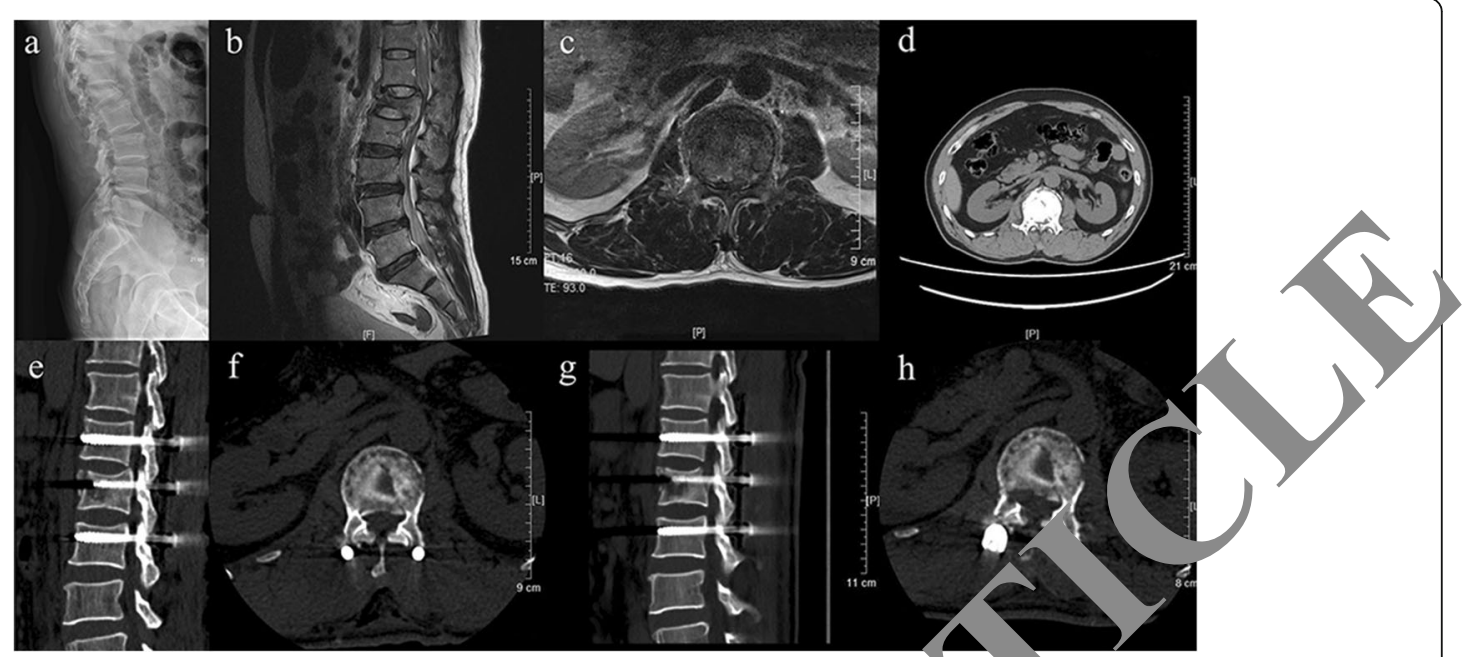

Fig. 2 Imaging of the patient on admission. Lateral radiograph (a) shows a fracture of the L1 vertehral body. O tomography, the retropulsion of bone fragments into the spinal canal is evident. Magnetic reso rang maging d T2-weighted image (b, c) also showed that bone fragments had retropulsed into the spinal canal and the dural sac was sero co $c$. The images of the patient were reexamined on the first day after PPSF. The sagittal (e) and axial (f) computed tomography show that the size of the fracture fragments in the

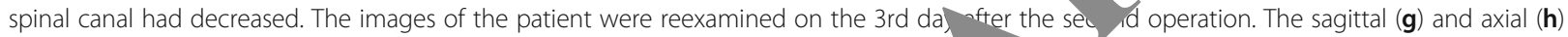
of the computed tomography showed no residual bone fragments in the spinal canal a ju lote decompression of the spinal cord

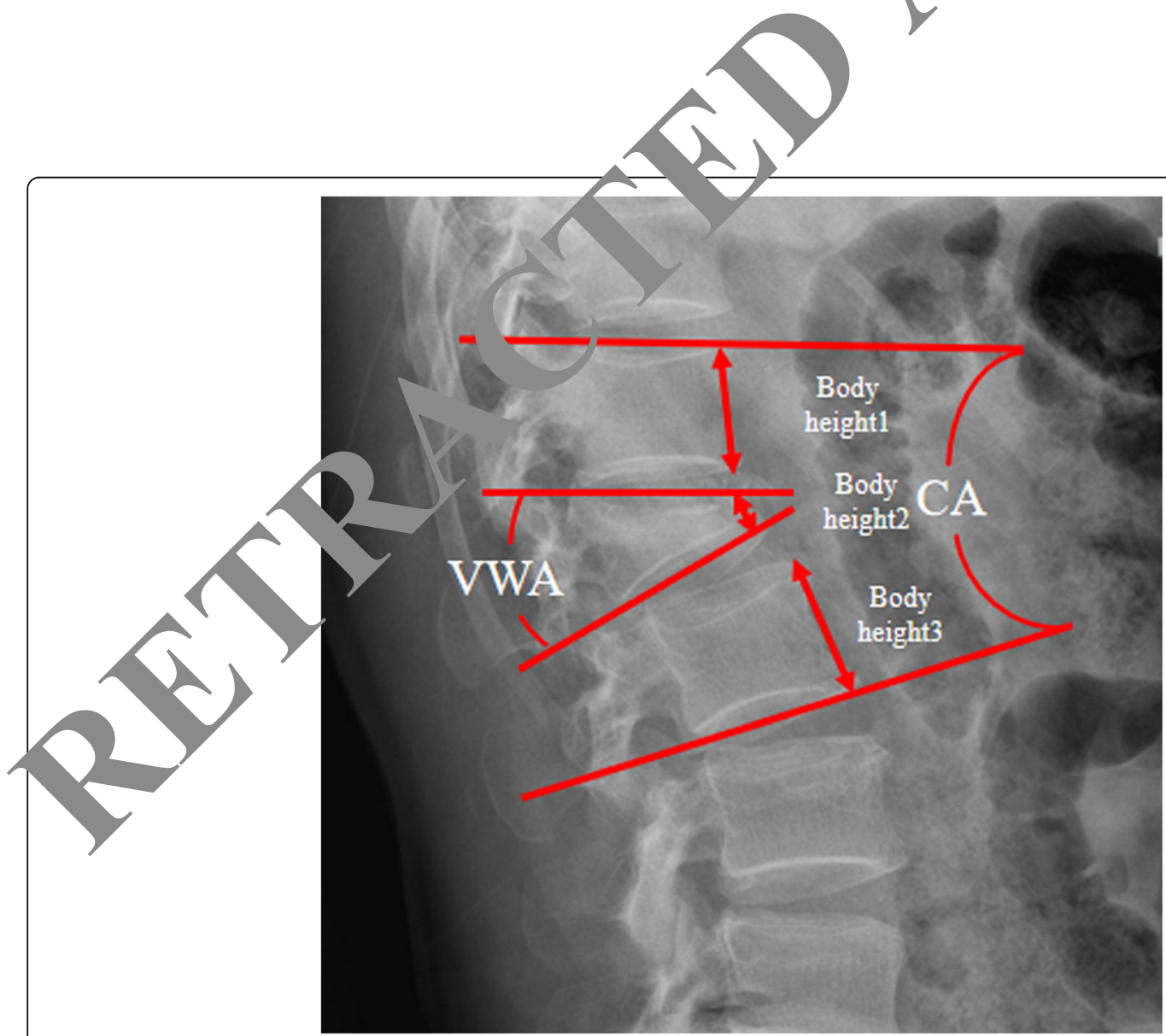

Fig. 3 Measurement of radiological parameters on a lateral neutral radiograph. CA, Cobb angle; WWA, vertebral wedge angle; vertebral body compression ratio $(\mathrm{VBCR})=[1-(2 \times$ body height 2$) /($ body height $1+3)] \times 100$ 
analog scale (VAS) was used to assess back pain of the patients preoperatively, 1 week postoperatively, and 12 months postoperatively. The Oswestry Disability Index (ODI) was used to assess disability preoperatively, 1 week postoperatively, and 12 months postoperatively. The Japanese Orthopedic Association score (JOA) was used to evaluate the clinical results preoperatively, 1 week postoperatively, and 12 months postoperatively. In addition, the Frankel classification of neurological deficits was used to assess the neurological status of the patients preoperatively and 12 months postoperatively.

\section{Radiographic evaluations}

Radiological examinations were performed preoperatively, 1 week postoperatively, and 12 months postoperatively. The mid-sagittal canal diameter (MSD) was identified as the distance between the posterior spinal canal boundary and the anterior spinal canal boundary. The MSD compression ratio (MSDCR) was calculated according to the following formula: [(V1 + V3)/2 - V2]/ $(\mathrm{V} 1+\mathrm{V} 3) / 2[18,19]$. The Cobb angle $(\mathrm{CA})$, vertebral body compression ratio (VBCR), and vertebral wedge angle (VWA) were measured on the lateral X-ray (Fig. 3). The CA reflected the change of the segment curve. The VWA usually reflected the anatomical shape of the fractured vertebra.

\section{Statistical analysis}

SPSS statistical software for Windows, versi o 4.0 (Ch. cago, IL, USA) was used for statistical analysis. "1 data were described as the mean. Statistic $t$ tests wer, used to compare the continuous vi iables pre- and

Table 1 Patient demographics and orioperative parameters

\begin{tabular}{ll}
\hline Characteristic & No. of patients \\
\hline Male $(n, \%)$ & $13(68.3)$ \\
Female $(n, \%)$ & $48.93 \pm 12.18$ \\
Age (years) & $1(2.4)$ \\
Level of fracture $\%$ & $7(17.1)$ \\
T11 & $20(48.8)$ \\
T12 & $9(22.0)$ \\
Type orracture (n, \%) & $4(9.8)$ \\
A3.1 & $26(63.4)$ \\
A3.2 & $10(24.4)$ \\
A3.3 & $5(12.2)$ \\
Length of stay & $10.66 \pm 5.07$ \\
Operation time (min) & $159.24 \pm 37.75$ \\
Follow-up (months) & $22.02 \pm 8.28$ \\
\hline
\end{tabular}

postoperatively, including the VAS, ODI, JOA, Frankel grade, VWA, CA, MSDCR, and VBCR. A value of $P<$ 0.05 was considered a significant difference.

\section{Results}

\section{Patient demographics}

As shown in Table 1, a total of 41 patients (25 er and 13 women) with single-segment TLBF were inclu ti is this study from August 2015 to October $\gamma^{1} 18$. Their o, erage age was $48.93 \pm 12.18$ years. Surgiral t. was 159.24 $\pm 37.75 \mathrm{~min}$, and in total, the ave age hosp stay was $10.66 \pm 5.07$ days and the avera follow up time was $22.02 \pm 8.28$ months. All pati $t_{s} h_{c}$ ingl -segment fractures, including one case th 11 level, seven cases at the T12 level, 20 cases he L1 le 1 , nine cases at the L2 level, and four cases at th 3 level. There were 26 cases $(63.4 \%)$ of type fractur, 10 cases $(24.4 \%)$ of type A3.2, and five res (2 2\%) of type A3.3.

\section{Outcomes he clinical data}

The patient/eeprted outcomes are shown in Table 2 and Table 3 There were significant improvements in the Vh $7.61 \pm 1.41$ vs. $1.17 \pm 0.80, P<0.001)$, the ODI (89.8 \pm 7.44 vs. $15.71 \pm 13.50, P<0.001)$, and the JOA s. re $(6.90 \pm 2.91$ vs. $24.90 \pm 3.03, P<0.001)$. According to Frankel's classification of neurological dysfunctions, there were two cases of grade A, six cases of grade C, 19 cases of grade D, and 14 cases of grade $\mathrm{E}$. All patients had no worsening of neurological function after surgery. Among the patients registered as grade $\mathrm{D}$, one case was still grade $\mathrm{D}$, and the rest had recovered to grade $\mathrm{E}$ at the 1 year follow-up. Among the patients registered as grade $\mathrm{C}$, three improved to grade $\mathrm{D}$ and three improved

Table 2 Functional score

\begin{tabular}{ll}
\hline & Results \\
\hline VAS (back pain) & $7.61 \pm 1.41$ \\
Preoperative & $3.15 \pm 1.04^{*}$ \\
1 week postoperatively & $1.17 \pm 0.80^{*}$ \\
12 months postoperatively & \\
ODI (\%) & $89.82 \pm 7.44$ \\
Preoperative & $55.34 \pm 9.31^{*}$ \\
1 week postoperatively & $15.71 \pm 13.50^{*}$ \\
12 months postoperatively & \\
JOA & $6.90 \pm 2.91$ \\
Preoperative & $17.10 \pm 2.54^{*}$ \\
1 week postoperatively & $24.90 \pm 3.03^{*}$ \\
12 months postoperatively
\end{tabular}

VAS visual analog scale, ODI Oswestry Disability Index, JOA Japanese Orthopaedic Association score

${ }^{*} P<0.001$, there was significant difference compared with preoperative 
Table 3 Preoperative and postoperative Frankel grades

\begin{tabular}{llllll}
\hline Preoperative & \multicolumn{5}{l}{$\mathbf{1 2}$ months postoperatively } \\
\cline { 2 - 5 } & E & D & C & B & A \\
\hline E & 14 & & & \\
D & 18 & 1 & & \\
C & 3 & 3 & & \\
B & & & & \\
A & & 2 & & & \\
\hline
\end{tabular}

to grade $\mathrm{E}$. Two patients with grade $\mathrm{A}$ recovered to grade $\mathrm{D}$ at the 1 year follow-up.

\section{Radiological data}

As shown in Table 4, the preoperative CA, VWA, and VBCR were significantly reduced after surgery and remained good at 1 year of follow-up $(P<0.05)$. The 26 patients only treated with PPSF surgery had an average preoperative MSDCR value of $30.49 \pm 16.25$, their postoperative MSDCR decreased to $13.29 \pm 8.76(P<0.001)$, and it remained good at the 1 year follow-up. The fifteen patients who were treated with TED surgery after PPSF had an average preoperative MSDCR of $67.39 \pm 14.50$. The MSDCR decreased to $4.63 \pm 5.39$ after two surgeries $(P<0.001)$, and remained good at the 1 year follow-up.

\section{Discussion}

After the occurrence of TLBF, the fractured pone in s bursts into the spinal canal and compress as se spin cord and the ventral side of the nerve root, ich is likely to cause nerve damage and f rther neuro, ogical dysfunction [4, 20]. Decompression surgery can help patients limit their secondary spinal cord injury and improve their neurological recovery after acute spinal cord injury [15]. At present, compared with posterior surgery, anterior surgery can achieve a more direct and complete decompression and promote better nerve recovery [14, 21]. However, the anterior approach also has som disadvantages, including the need for large surgi al exposures, the risk of large vessel damage, persistent pain after surgery, and pulmonary complications [22]. P ior surgery typically involves convention noster or fixation combined with one-stage spipal cana cicion and decompression. Posterior decomp ession is lfss invasive than anterior decompression but t as th orough as anterior decompression. Becaus of th uirect spinal decompression effect of PPSF, ome TLBF can be decompressed withor $t_{\text {a }}$ inal incision, and the symptoms of neurological defici san be completely relieved. However, neitb r a erior nor posterior decompression surgery can ace singuish between patients who need direct decon ession and those who do not need it, and u sossary decompression is therefore performed in patie, its who can completely recover from their neurological deficits after posterior pedicle screw fixa $n$. The unnecessary decompression may cause iatogen : injury during the surgery and may increase the oi secondary spinal cord injury.

In view of these considerations, we proposed a treatment strategy that, for the first time, involved PPSF combined with selective TED. This treatment approach has the following advantages: (1) accurate and selective spinal decompression is achieved. PPSF and TED are performed at different stages, taking advantage of the

Table 4 X-radiography and $C T$ data

\begin{tabular}{|c|c|c|c|}
\hline & oper-s & 1 week postoperatively & 12 months postoperatively \\
\hline \multicolumn{4}{|l|}{$\overline{C A}\left({ }^{\circ}\right)$} \\
\hline A group & & $5.59 \pm 4.42^{* * *}$ & $5.57 \pm 4.09^{\mathrm{a}}$ \\
\hline B group & 7.59 & $6.49 \pm 4.31^{* * *}$ & $6.78 \pm 4.96^{\mathrm{a}}$ \\
\hline \multicolumn{4}{|l|}{ WA $\left(^{\circ}\right)$} \\
\hline & $14.19 \pm 7.89$ & $5.96 \pm 2.58^{*}$ & $5.67 \pm 2.42^{\mathrm{a}}$ \\
\hline & $16.52 \pm 5.74$ & $6.77 \pm 2.33^{* * *}$ & $6.95 \pm 2.41^{a}$ \\
\hline & $39.27 \pm 17.29$ & $6.13 \pm 5.25^{* *}$ & $5.99 \pm 4.98^{\mathrm{a}}$ \\
\hline & $37.58 \pm 16.09$ & $6.65 \pm 10.84^{* * *}$ & $7.47 \pm 9.06^{\mathrm{a}}$ \\
\hline \multicolumn{4}{|l|}{ MSDCR (\%) } \\
\hline A group & $67.39 \pm 14.50$ & $4.63 \pm 5.39^{* * *}$ & $4.61 \pm 5.60^{\mathrm{a}}$ \\
\hline B group & $30.49 \pm 16.25$ & $13.29 \pm 8.76^{* * *}$ & $12.33 \pm 7.02^{\mathrm{a}}$ \\
\hline
\end{tabular}

A group = the 15 patients who underwent TED surgery and PPSF surgery. B group $=$ the 26 patients who underwent only PPSF surgery $C A$ Cobb angle, VWA vertebral wedge angle, VBCR vertebral body compression ratio, MSDCR mid-sagittal canal diameter compression ratio *P $<0.05$

${ }^{* *} P<0.01$

***P $P 0.001$

${ }^{\mathrm{a}} P>0.05$ 
indirect spinal decompression effect of PPSF. For the patients who completely recovered neurological function after PPSF, excessive decompression was avoided; for patients with poor postoperative neurological recovery, TED surgery was then performed to promote their neurological recovery. (2) Compared with both anterior surgery with direct decompression and posterior spinal canal decompression, TED surgery has the advantages of causing less injury, and its spinal canal decompression effect is similar to that of anterior decompression surgery. (3) Both PPSF and TED are minimally invasive surgeries, which have the advantages of less trauma, less bleeding, less pain, and faster postoperative recovery, and there are fewer complications related to the approach $[7,8]$. (4) Local infiltration anesthesia combined with intravenous anesthesia ensured that the patient was awake during the surgery, so the patient could provide timely feedback to the surgeon to maximize the patient's safety.

Zhao et al. [23] reported the first case of PPSF surgery combined with a transforaminal endoscope in the treatment of burst fractures. They believed that the procedure was applicable to the transverse and sagittal diameters of spinal canal bone masses not greater than $15 \mathrm{~mm}$ and $10 \mathrm{~mm}$, respectively, and radiological evaluation of a compressed area not greater than $50 \%$ of the TLBF [23]. Based on these requirements, we furt proved the TED technology and developed ute $t_{1}$ nerve root decompression method, in which range of decompression under the percutaneous enaosco ${ }_{1}$ is significantly increased by decompression from the en,rance exiting the nerve root and traversin the nerve root to the inner ventral of the dural sac an ontralateral traversing nerve root. Here, by co ' ining PPSF with TED, we could achieve perfect decomp on and complete neurological recovery $\mathrm{BF}$ ratients with both $90 \%$ MSDCR and 90\% sp. ca conpression areas.

Of the 41 patie wis wo burst fractures who underwent PPSF surgery is study 26 of them had almost normal neurolngical to tion (14 had no nerve damage before sur ery), and, 0 further decompression of the spinal a 1 kas required. Fifteen of these patients still had onif t herve injury or hip and lower extremity rve irritation symptoms, so they then received TED u. r two-stage local infiltration anesthesia. Their lower extro ty pain was completely relieved after the surgery, their neural function was also significantly restored, and there were no nerve injuries or other complications. The fifteen patients who underwent second stage TED surgery had an MSDCR of $67.39 \pm 14.50$ before surgery and a reduction to $4.63 \pm 5.39$ after surgery, indicating that their neural function was significantly restored. The spinal canal bone was quickly and completely cleared, which indicated that TED fully achieved the effect of anterior decompression with fewer injuries and complications. Our results showed that 20 of 41 cases had MSDCR $<1 / 3$, and their symptoms were completely relieved after PPSF; 10 cases had MSDCR between $1 / 3$ and $2 / 3$, and 6 of them had complete relief. The other four cases required further spinal canal decompressio surgery, and the 11 cases with MSDCR $>2 / 3$ reg red further spinal canal decompression surgery.

We therefore believe that TLBF can be dividea three degrees according to the preops tive MSBCR: MSDCR $<1 / 3$, degree I; $1 / 3<$ MSPCR < d d gree II; and MSDCR $>2 / 3$, degree III. of the fiftes $n$ patients who required secondary surgety, ven had preoperative MSDCR > 2/3; the other fou ad perative MSDCR between $1 / 3$ and $2 / 3$, bat the e mass in the spinal canal was sideways ra mpressed more heavily than in the mid-sagittal region. nerally, for MSDCR $<1 / 3$, no decompression needed, for MSDCR $>2 / 3$, decompression of the in al should be performed; for $1 / 3$ $<\operatorname{MSDCR}<2 / 3$, hether spinal decompression should be perfor depends on the specific situation of the patient.

This findi og is significant for predicting whether TLBF $\mathrm{req}_{\mathrm{f}}$ es spinal canal decompression. The decision whet $r$ to perform a second stage TED surgery was $1, n / y$ based on the neurological recovery of patients after PPSF. Of the fifteen patients who underwent second stage TED surgery, ten cases still had significant hip and lower limb nerve irritation symptoms and mild neurological damage after PPSF, and five cases still had significant neurological damage, and muscle strength less than grade 3 with poor function in urination and defecation. Therefore, we believe that the indications for secondary decompression surgery include (1) persistent significant neurological impairment, such as obvious muscle loss, sensory disturbances, or poor urination and defecation function; and (2) mild neurological impairment with obvious hip and lower limbs and nerve irritation symptoms remaining.

In summary, PPSF combined with selective TED is suitable for all types of TLBF except dislocations. In this era of minimally invasive spine treatments, this combination treatment is expected to become the preferred method of treating TLBF. However, this study had significant limitations. First, the small sample size from a single center may have affected the conclusions. Second, this study was a retrospective study. To improve the efficacy of PPSF combined with selective TED in the treatment of TLBF and to validate the grading theory of TLBF, a larger, multicenter prospective study is needed in the future.

\section{Conclusion}

Our results showed that PPSF combined with selective TED had excellent curative effects on TLBF with high 
safety, little secondary injury, and broad indications. This combination treatment accurately distinguished patients who did not need spinal canal decompression after posterior fixation. In this era of minimally invasive surgery, spine PPSF combined with selective TED may be an effective alternative to classic open surgical approaches.

\section{Abbreviations}

TLBF: Thoracolumbar burst fracture; PPSF: Percutaneous pedicle screw fixation; TED: Transforaminal endoscopic decompression; CT: Computed tomography; VAS: Visual analog scale; ODI: Oswestry Disability Index; JOA: Japanese Orthopedic Association score; MSD: Mid-sagittal canal diameter; MSDCR: Mid-sagittal canal diameter compression ratio; CA: Cobb angle; VBCR: Vertebral body compression ratio; WWA: Vertebral wedge angle

\section{Acknowledgements}

We would like to thank all of the staff of the Department of Spine Surgery, Affiliated Hospital of Chengde Medical University for their contributions to our research.

\section{Authors' contributions}

Authors $\mathrm{ZH} \mathrm{H}$ and $\mathrm{CL} \mathrm{Z}$ made substantial contributions to the design of this study. Authors YX T, C H, and ZY F collected the data. Authors ZH H analyzed the data. Author $\mathrm{ZH} \mathrm{H}$ wrote the manuscript. Authors $\mathrm{ZH} \mathrm{H}$ and $\mathrm{CL} Z$ revised the manuscript. All authors read and approved the final manuscript.

\section{Funding}

We received no external funding for this study.
6. Wang J, Zhou Y, Zhang ZF, Li CQ, Zheng WJ, Liu J. Radiological study on disc degeneration of thoracolumbar burst fractures treated by percutaneous pedicle screw fixation. Eur Spine J. 2013;22(3):489-94.

7. Gong Y, Fu G, Li B, Li Y, Yang X. Comparison of the effects of minimally invasive percutaneous pedicle screws osteosynthesis and open surgery on repairing the pain, inflammation and recovery of thoracolumbar vertebra fracture. Exp Ther Med. 2017;14(5):4091-6.

8. Sun XY, Zhang XN, Hai Y. Percutaneous versus traditional and par spmal posterior open approaches for treatment of thoracolumbar frar ures without neurologic deficit: a meta-analysis. Eur Spine J. 2017,20

9. Proietti L, Scaramuzzo L, Schirò GR, Sessa S, D'Aurizio G, Tamburre Posterior percutaneous reduction and fixation of thor co-lumbar burs fractures. Orthop Traumatol Surg Res. 2014;100(5):

10. Xu XY, Yan ZJ, Ma Q, Chen L, Ke ZY, Chen F, et Clinica plicat on of the paraspinal erector approach for spinal canal aecompression apper lumber burst fractures. J Orthop Surg Res. 14;9(1):105.

11. Yang S, Shang DP, Lu JM, Liu JF, Fu Dos, Zh et al. Modified posterior short-segment pedicle screw instrlan ation burst fractures with incomplete neurological de it. Wo Veurosurg. 2018;119:e977-e85.

12. Mehraj M, Malik FH. Early clir al results on ty same-segment posterior fixation in thoracolumbar ours ctures. Or..0p Traumatol Rehabil. 2018; 20(3):211-7.

13. Kocis J, Kelbl M, Ko Vávrat T. Pe ataneous versus open pedicle screw fixation for treat ent o ype A thoracolumbar fractures. Eur J Trauma Emerg Surg. 202

14. Sasso RC, Best NM, $\quad$ TM, Mcguire RA. Anterior-only stabilization of three-co mn thoracoly r.bar injuries. J Spinal Disord Techn. 2005; 18(Suppl

15. Benzel EC, 1 son $\int$. Functional recovery after decompressive operation for thoracic an L lumbar spine fractures. Neurosurgery. 1986;19(5):772-8.

"ood KB, Li, N, Lebl DR, Lebl DS, Ploumis A. Management of thoracolumbar fractures. Spine J. 2014;14(1):145-64.

ake KJ, Schroeder GD, Vaccaro AR, Oner C. AOSpine classification grems (subaxial, thoracolumbar). J Orthopaed Trauma. 2017;31:S14-23. rashimoto T, Kaneda K, Abumi K. Relationship between traumatic spinal canal stenosis and neurologic deficits in thoracolumbar burst fractures. Spine. 1988;13(11):1268-72

19. Willén J, Anderson J, Toomoka K, Singer K. The natural history of burst fractures at the thoracolumbar junction. J Spinal Disord. 1990;3(1):39-46.

20. Walker CT, Xu DS, Godzik J, Turner JD, Uribe JS, Smith WD. Minimally invasive surgery for thoracolumbar spinal trauma. Ann Transl Med. 2018;6(6):102.

21. Kaneda K, Taneichi H, Abumi K, Hashimoto T, Satoh S, Fujiya M. Anterior decompression and stabilization with the Kaneda device for thoracolumbar burst fractures associated with neurological deficits. J Bone Joint Surg Am Volume. 1997;79(1):69-83.

22. Park SH, Kim SD, Moon BJ, Lee SS, Lee JK. Short segment percutaneous pedicle screw fixation after direct spinal canal decompression in thoracolumbar burst fractures: an alternative option. J Clin Neurosci. 2018, 53:48-54

23. Wang Y, Ning C, Yao L, Huang X, Zhao C, Chen B, et al. Transforaminal endoscopy in lumbar burst fracture: a case report. Medicine. 2017;96(46): e8640.

\section{Publisher's Note}

Springer Nature remains neutral with regard to jurisdictional claims in published maps and institutional affiliations.

Ready to submit your research? Choose BMC and benefit from:

- fast, convenient online submission

- thorough peer review by experienced researchers in your field

- rapid publication on acceptance

- support for research data, including large and complex data types

- gold Open Access which fosters wider collaboration and increased citations

- maximum visibility for your research: over $100 \mathrm{M}$ website views per year

At $\mathrm{BMC}$, research is always in progress.

Learn more biomedcentral.com/submissions 